\title{
Using the Budyko framework to evaluate the human imprint on long-term surface water partitioning across India
}

\author{
Anav Vora ${ }^{1}$ and Riddhi Singh ${ }^{1}$ \\ ${ }^{1}$ Indian Institute of Technology Bombay
}

September 21, 2020

\begin{abstract}
The Budyko curve, relating a catchment's water and energy balance, provides a useful tool to analyse how physio-climatic and socio-economic characteristics may impact long-term runoff. Often a parametric form of the curve, the Fu's equation, is used to represent the catchment's long-term water partitioning behaviour. Fu's parameter $\omega$, typically derived from observed climate and runoff data, can further be related to catchments' physio-climatic characteristics to enable understanding the main drivers of their water balance. At times, prior analyses have reported potentially conflicting controls of characteristics on $\omega$. Based on the rationale that several hydrological processes act across varying spatio-temporal scales, we hypothesize that the impact of a physio-climatic factor on $\omega$ is driven by its broader regional setting. We test our hypothesis by developing relationships between $\omega$ and a curated database of 33 physio-climatic and socio-economic characteristics for 534 regional divisions of India. We employ two related data-space splitting algorithms: classification and regression trees (CART) and random forest (RF) to study the effects of potential controlling factors within their regional context. The algorithms diagnose a hierarchy of representative vegetation, climate, soil, land use land cover, topography and anthropogenic controls. The most important characteristics controlling $\omega$ were found to be: long-term temperature, percentage of short rooted vegetation, population density, and longterm precipitation. We show the significance of considering the regional context by highlighting contrasting effects of two factors: long-term temperature and the proportion of sand to silt content on $\omega$. Anthropogenic activities were found to be decisive in governing the effect of long-term temperature, indicating their influence on hydrological processes across the Indian subcontinent.
\end{abstract}

Using the Budyko framework to evaluate the human imprint on long-term surface water partitioning across India

\section{Running Head: HUMAN INFLUENCES WATER PARTITIONING BUDYKO INDIA}

Anav Vora ${ }^{1}$, Riddhi Singh ${ }^{1,2}$

${ }^{1}$ Department of Civil Engineering, Indian Institute of Technology Bombay, Mumbai, India

${ }^{2}$ Interdisciplinary Programme in Climate Studies, Indian Institute of Technology Bombay, Mumbai, India

Keywords : Budyko; India; Fu's parameter; CART; random forest; human impact

Short Informative :

- Use machine learning algorithms to identify dominant factors governing Fu's parameter $\omega$ across landmasses of India.

- Show that the influence of a physio-climatic factor, such as temperature, on $\omega$ may be governed by the broader regional setting as governed by other factors such as population density and cultivation.

- Highlight the significance of using a classification and regression (CART) tree based framework to identify nested controls on the hydrological processes governing surface water partitioning. 
- Show that anthropogenic activities are decisive in governing the effect of long-term temperature on $\omega$ in heavily cultivated landmasses of India

Acknowledgement: The data sets used in the study are freely available for academic research in the public domain. The calibrated omega values and associated characteristics values for each regional division along with the codes are provided at:https://riddhisingh.weebly.com/codeanddata.html. We acknowledge and thank Sai Veena and Ankit Deshmukh for their assistance with data extraction and assimilation. A previous version of this paper exists in a publicly accessible pre-print repository at:

https://www.authorea.com/users/348666/articles/473882-using-the-budyko-framework-to-evaluate-thehuman-imprint-on-long-term-surface-water-partitioning-across-india

Data Availability Statement: The calibrated omega values and associated characteristics values for each regional division along with the codes are provided at:https://riddhisingh.weebly.com/codeanddata.html . The data used to estimate various physio-climatic and socio-economic characteristics were derived from the following resources available in the public domain:

1. Temperature and precipitation daily data, India Meteorological Department: http://imdpune.gov.in/Clim_Pred_LRF_New/Grided_Data_Download.html\#

2. NDVI, Global Inventory Monitoring and Modelling System's (GIMMS): https://ecocast.arc.nasa.gov/data/pub/gimms/3g.v0/

3. Settlements, Anthropogenic Biomes of the World, Version 2: 2000: https://doi.org/10.7927/H4D798B9

4. PESWC, Global plant extractable soil water capacity maps: https://doi.org/10.3334/ORNLDAAC/545

5. Topographical data (Aspect, Elevation, Slope, and SlopeTan): https://earthexplorer.usgs.gov/

6. Saturated hydraulic conductivity, GLobal HYdrogeology MaPS (GLHYMPS): https://doi.org/10.5683/SP2/DLGXYO

7. Soil composition data, SoilGrids1km: https://soilgrids.org/

8. Land cover data, Global Land Cover (GLC2000) maps for South Asia: https://forobs.jrc.ec.europa.eu/products/glc2000/products.php

9. Data on existing dams, Global Reservoir and Dam Database (v1.01): https://doi.org/10.7927/H4N877QK

10. Population data, Census India, 2011: https://censusindia.gov.in/2011census/population_enumeration.html

\section{Hosted file}

MainText.docx available at https://authorea.com/users/348666/articles/482248-using-thebudyko-framework-to-evaluate-the-human-imprint-on-long-term-surface-water-partitioningacross-india

\section{Hosted file}

Table 1.docx available at https://authorea.com/users/348666/articles/482248-using-thebudyko-framework-to-evaluate-the-human-imprint-on-long-term-surface-water-partitioningacross-india

\section{Hosted file}

Table 2.docx available at https://authorea.com/users/348666/articles/482248-using-thebudyko-framework-to-evaluate-the-human-imprint-on-long-term-surface-water-partitioningacross-india

\section{Hosted file}

Table 3.docx available at https://authorea.com/users/348666/articles/482248-using-thebudyko-framework-to-evaluate-the-human-imprint-on-long-term-surface-water-partitioningacross-india 


\section{Hosted file}

Table 4.docx available at https://authorea.com/users/348666/articles/482248-using-thebudyko-framework-to-evaluate-the-human-imprint-on-long-term-surface-water-partitioningacross-india

figures/Figure1/Figure1-eps-converted-to.pdf 
figures/Figure2/Figure2-eps-converted-to.pdf 
figures/Figure3/Figure3-eps-converted-to.pdf

\section{Hosted file}

Figure4.eps available at https://authorea.com/users/348666/articles/482248-using-the-budykoframework-to-evaluate-the-human-imprint-on-long-term-surface-water-partitioning-acrossindia 
figures/Figure5/Figure5-eps-converted-to.pdf

\section{Hosted file}

Figure6.eps available at https://authorea.com/users/348666/articles/482248-using-the-budykoframework-to-evaluate-the-human-imprint-on-long-term-surface-water-partitioning-acrossindia 
figures/Figure7/Figure7-eps-converted-to.pdf 
figures/Figure8/Figure8-eps-converted-to.pdf 
figures/Figure9/Figure9-eps-converted-to.pdf 